Revista Eletrônica de Direito Processual - REDP. Volume 16. Julho a dezembro de 2015

Periódico Semestral da Pós-Graduação Stricto Sensu em Direito Processual da UERJ

Patrono: José Carlos Barbosa Moreira. ISSN 1982-7636. pp. 436-448 http://www.e-publicacoes.uerj.br/index.php/redp/index

\title{
A DESCONSIDERAÇÃO DA PERSONALIDADE JURÍDICA NO NOVO CÓDIGO DE PROCESSO CIVIL ${ }^{1}$
}

\section{THE DISREGARD DOCTRINE IN NEW CIVIL PROCEDURE CODE}

Paulo Roberto Pegoraro Junior

Doutorando em Direito pela Pontifícia Universidade Católica do Rio Grande do Sul (PUC/RS). Mestre em Direito

Processual e Cidadania pela Universidade Paranaense (UNIPAR). Professor de Direito Processual Civil da Faculdade de Ciências Sociais Aplicadas de Cascavel (UNIVEL). Advogado. paulopegorarojr@hotmail.com

RESUMO: O novo Código de Processo Civil tratou de regular o procedimento aplicável à desconsideração da personalidade jurídica, de modo a assegurar a plenitude do contraditório pévio e admitindo a desconsideração inversa. A inovação permite a adequação formal a importante instrumento de efetividade material no processo civil, embora já se identifiquem alguns pontos objeto de controvérsias.

PALAVRAS-ChAVE: Desconsideração; Pessoa Jurídica; Código de Processo Civil; Incidente.

ABSTRACT: The new Civil Procedure Code sought to regulate the procedure for piercing the corporate veil in order to ensure the fullness of pévio contradictory and admitting the reverse disregard. Innovation allows formal fitness for important tool material effectiveness in the civil process, although already identify some object points of controversy.

KEYWORDS: Disregard; Legal Person; Code of Civil Procedure; Incident.

\footnotetext{
${ }^{1}$ Artigo recebido em 26/06/2015 e aprovado em 22/11/2015.
} 
Revista Eletrônica de Direito Processual - REDP. Volume 16. Julho a dezembro de 2015

Periódico Semestral da Pós-Graduação Stricto Sensu em Direito Processual da UERJ

Patrono: José Carlos Barbosa Moreira. ISSN 1982-7636. pp. 436-448 http://www.e-publicacoes.uerj.br/index.php/redp/index

$\mathrm{O}$ novo Código de Processo Civil tratou de regular o procedimento aplicável à desconsideração da personalidade jurídica, em seus artigos 133/137, fomentando importante adequação formal ao instrumento.

Vários diplomas estabelecem os requisitos materiais para desconsideração da personalidade jurídica. O Código Civil estabelece regra geral em seu art. 50 que autoriza a desconsideração "em caso de abuso da personalidade jurídica, caracterizado pelo desvio de finalidade, ou pela confusão patrimonial".

O Código de Defesa do Consumidor, em seu art. 28, permite a aplicação do instituto quando "em detrimento do consumidor, houver abuso de direito, excesso de poder, infração da lei, fato ou ato ilícito ou violação dos estatutos ou contrato social”, ou ainda quando houver "falência, estado de insolvência, encerramento ou inatividade da pessoa jurídica provocados por má administração", autorizando, ainda, a desconsideração "sempre que sua personalidade for, de alguma forma, obstáculo ao ressarcimento dos prejuízos causados aos consumidores" (art. 28, p. 50, CDC). Por seu turno, o direito do trabalho alberga a possibilidade da desconsideração "sempre que uma ou mais empresas, tendo, embora, cada uma delas, personalidade jurídica própria, estiverem sob a direção, controle ou administração de outra, constituindo grupo industrial, comercial ou de qualquer outra atividade econômica, serão, para os efeitos da relação de emprego, solidariamente responsáveis a empresa principal e cada uma das subordinadas" (art. $2^{\circ}$, p. $2^{\circ}$, CLT).

Também as regras tributárias admitem a desconsideração (arts. 134 e 135, CTN). Daí porque o Superior Tribunal de Justiça já teve oportunidade de apontar:

A criação teórica da pessoa jurídica foi avanço que permitiu o desenvolvimento da atividade econômica, ensejando a limitação dos riscos do empreendedor ao patrimônio destacado para tal fim. Abusos no uso da personalidade jurídica justificaram, em lenta evolução jurisprudencial, posteriormente incorporada ao direito positivo brasileiro, a tipificação de hipóteses em que se autoriza o levantamento do véu da personalidade jurídica para atingir o patrimônio de sócios que dela dolosamente se prevaleceram para finalidades ilícitas. Tratando- 
Revista Eletrônica de Direito Processual - REDP. Volume 16. Julho a dezembro de 2015

Periódico Semestral da Pós-Graduação Stricto Sensu em Direito Processual da UERJ

Patrono: José Carlos Barbosa Moreira. ISSN 1982-7636. pp. 436-448 http://www.e-publicacoes.uerj.br/index.php/redp/index

se de regra de exceção, de restrição ao princípio da autonomia patrimonial da pessoa jurídica, a interpretação que melhor se coaduna com o art. 50 do Código Civil é a que relega sua aplicação a casos extremos, em que a pessoa jurídica tenha sido instrumento para fins fraudulentos, configurado mediante o desvio da finalidade institucional ou a confusão patrimonial. (EREsp 1306553/SC, Rel. Ministra Maria Isabel Gallotti, Segunda Seção, julgado em 10/12/2014, DJe $12 / 12 / 2014)$

Assim, "para haver a desconsideração da personalidade jurídica, as instâncias ordinárias devem, fundamentadamente, concluir pela ocorrência do desvio de sua finalidade ou confusão patrimonial desta com a de seus sócios, requisitos objetivos sem os quais a medida torna-se incabível” (REsp 1098712/RS, Rel. Ministro Aldir Passarinho Junior, Quarta Turma, julgado em 17/06/2010, DJe 04/08/2010). A despeito, por exemplo, da adoção da Súmula 435 pelo STJ, no sentido de que "presume-se dissolvida irregularmente a empresa que deixar de funcionar no seu domicílio fiscal, sem comunicação aos órgãos competentes, legitimando o redirecionamento da execução fiscal para o sócio-gerente", o mesmo tribunal já vinha definindo que "a mudança de endereço da empresa executada associada à inexistência de bens capazes de satisfazer o crédito pleiteado pelo exequente não constituem motivos suficientes para a desconsideração da sua personalidade jurídica" (REsp 970.635/SP, Rel. Ministra Nancy Andrighi, Terceira Turma, julgado em 10/11/2009, DJe 01/12/2009).

A vivência forense tem ensinado que a apreciação da desconsideração acaba adotando a chamada "teoria menor" para os executivos fiscais e as execuções trabalhistas e a "teoria maior" para as execuções cíveis: "de um lado, a teoria maior, em que a autonomia patrimonial é desconsiderada quando caracterizada a fraude ou a confusão patrimonial. De outro lado, a teoria menor, para qual é suficiente a simples inexistência de ativos" (Coelho, 2014), embora o STJ venha insistindo na tese que a aplicação da "teoria maior" é aquela que foi adotada pelo ordenamento brasileiro:

1. A criação teórica da pessoa jurídica foi avanço que permitiu o desenvolvimento da atividade econômica, ensejando a limitação dos riscos do 
Revista Eletrônica de Direito Processual - REDP. Volume 16. Julho a dezembro de 2015

Periódico Semestral da Pós-Graduação Stricto Sensu em Direito Processual da UERJ

Patrono: José Carlos Barbosa Moreira. ISSN 1982-7636. pp. 436-448 http://www.e-publicacoes.uerj.br/index.php/redp/index

empreendedor ao patrimônio destacado para tal fim. Abusos no uso da personalidade jurídica justificaram, em lenta evolução jurisprudencial, posteriormente incorporada ao direito positivo brasileiro, a tipificação de hipóteses em que se autoriza o levantamento do véu da personalidade jurídica para atingir o patrimônio de sócios que dela dolosamente se prevaleceram para finalidades ilícitas. Tratando-se de regra de exceção, de restrição ao princípio da autonomia patrimonial da pessoa jurídica, a interpretação que melhor se coaduna com o art. 50 do Código Civil é a que relega sua aplicação a casos extremos, em que a pessoa jurídica tenha sido instrumento para fins fraudulentos, configurado mediante o desvio da finalidade institucional ou a confusão patrimonial.

2. O encerramento das atividades ou dissolução, ainda que irregulares, da sociedade não são causas, por si só, para a desconsideração da personalidade jurídica, nos termos do Código Civil.

3. Embargos de divergência acolhidos.

(EREsp 1306553/SC, Rel. Ministra Maria Isabel Gallotti, Segunda Seção, julgado em 10/12/2014, DJe 12/12/2014)

O procedimento até aqui adotado, talvez fruto da ausência de regramento, talvez decorrente da ânsia de efetividade, vinha sendo pelo deferimento da desconsideração sem o prévio e amplo contraditório, em posição reiteradas vezes acolhida pelo Superior Tribunal de Justiça: “A superação da pessoa jurídica afirma-se como um incidente processual e não como um processo incidente, razão pela qual pode ser deferida nos próprios autos, dispensando-se também a citação dos sócios, em desfavor de quem foi superada a pessoa jurídica, bastando a defesa apresentada a posteriori, mediante embargos, impugnação ao cumprimento de sentença ou exceção de pré-executividade." (REsp 1096604/DF, Rel. Ministro Luis Felipe Salomão, Quarta Turma, julgado em 02/08/2012, DJe 16/10/2012); "Esta Corte firmou entendimento de que é prescindível a citação prévia dos sócios para a desconsideração da personalidade jurídica da sociedade empresária, sendo forçosa a demonstração do efetivo prejuízo advindo do contraditório diferido" (AgRg no REsp 1459831/MS, Rel. Ministro Marco Aurélio Bellizze, Terceira Turma, julgado em 21/10/2014, DJe 28/10/2014). 
Revista Eletrônica de Direito Processual - REDP. Volume 16. Julho a dezembro de 2015

Periódico Semestral da Pós-Graduação Stricto Sensu em Direito Processual da UERJ

Patrono: José Carlos Barbosa Moreira. ISSN 1982-7636. pp. 436-448 http://www.e-publicacoes.uerj.br/index.php/redp/index

A tônica de assegurar a plenitude do contraditório do novo diploma processual, expresso, por exemplo, na proibição das decisões sem que uma das partes seja previamente ouvida (art. $9^{\circ}, \mathrm{NCPC}$ ), conduz à compreensão da nova exigência de que a instauração incidental do pedido implique a "citação" do sócio ou da pessoa jurídica para que se manifeste e requeira as provas cabíveis no prazo de 15 dias (art. 135, NCPC).

Caso o pedido já tenha sido formulado na própria inicial pelo autor, evidente que não haverá nova necessidade de manifestação, posto que a parte poderá se insurgir já a partir da citação, exercendo a plenitude do contraditório desde logo, muito embora a desconsideração se admita "em todas as fases do processo de conhecimento, no cumprimento de sentença e na execução fundada em título executivo extrajudicial" (art. 134), o que exigirá, no mais das vezes, que a defesa por parte do sócio se dê não apenas em sede de contestação, mas também em impugnação ao cumprimento de sentença, com limitação de cognição no âmbito horizontal, e em embargos à execução. Daí que tenha o Fórum Permanente de Processualistas Civis editado o Enunciado 248, por ocasião da Carta de Vitória: “Quando a desconsideração da personalidade jurídica for requerida na petição inicial, incumbe ao sócio ou a pessoa jurídica, na contestação, impugnar não somente a própria desconsideração, mas também os demais pontos da causa".

Há um complicador decorrente da inclusão do sócio ou da empresa já na petição inicial, no caso do processo de conhecimento, tanto pelo fato de que talvez ainda não se possa caracterizar ao menos a insolvência da empresa, tanto porque deve ser assegurado o direito de preferência, pelo sócio, de que sejam primeiros excutidos os bens da sociedade (art. 596, CPC/1973, art. 795, CPC/2015), restando, neste caso, a hipótese de que o sócio indique a localização dos bens da sociedade. É de se distinguir a presença dos requisitos autorizadores da desconsideração, da execução em si, pois em tese não é apenas a insolvência da empresa que conduz à aplicação da doutrina, da execução posterior, que envolve a penhora de bens. Mas caberá ao autor, ao se incluir o sócio ou a empresa na inicial, apontar os elementos que caracterizem a possibilidade da quebra, não podendo se limitar à pura e simples inclusão dos sócios sem fundamentação, caso em que se terá flagrante ilegitimidade passiva. 
Revista Eletrônica de Direito Processual - REDP. Volume 16. Julho a dezembro de 2015

Periódico Semestral da Pós-Graduação Stricto Sensu em Direito Processual da UERJ

Patrono: José Carlos Barbosa Moreira. ISSN 1982-7636. pp. 436-448 http://www.e-publicacoes.uerj.br/index.php/redp/index

Ressalta a ideia de que não seja o sócio ou a empresa (no caso da desconsideração da personalidade jurídica inversa, também admitida pelo novo CPC, art. 133, p. $2^{\circ}$ ) tomado de surpresa com o bloqueio ou a penhora de bens, apesar de que não se impede que a providência venha a ser adotada cautelarmente, na presença de elementos que apontem para a dissipação do patrimônio ou no risco de que a citação possa acarretar a insolvência tanto da empresa quanto do sócio.

Ao se assegurar a oportunidade de produção de provas, pelo sócio, este terá a possibilidade de comprovar que não praticou atos que configurem desvio de finalidade ou confusão patrimonial, coisa que não vinha sendo admitida de modo diferido, ainda mais no âmbito da estreita via probatória da execução, onde é evidente a limitação quanto à produção de provas que não sejam de natureza documental.

O novo CPC tratou de admitir expressamente a desconsideração inversa, que se dá quando os bens da pessoa física são desviados para pessoa jurídica, tal como se sucede em casos envolvendo divórcio. O STJ já vinha admitindo a possibilidade, para atingir o ente coletivo e seu patrimônio social, de modo a responsabilizar a pessoa jurídica por obrigações do sócio controlador: "É possível a desconsideração inversa da personalidade jurídica sempre que o cônjuge ou companheiro empresário valer-se de pessoa jurídica por ele controlada, ou de interposta pessoa física, a fim de subtrair do outro cônjuge ou companheiro direitos oriundos da sociedade afetiva" (REsp 1236916/RS, Rel. Ministra Nancy Andrighi, Terceira Turma, julgado em 22/10/2013, DJe 28/10/2013).

A redação do artigo 133 dá a entender que o pedido de desconsideração deve sempre decorrer de requerimento da parte ou do Ministério Público, nas causas em que intervir, não podendo ser instaurado de ofício pelo magistrado. Para Luiz Guilherme Marinoni et al (2015), contudo, “nada impede, porém, que o juiz dê início ao incidente também de ofício, sempre que o direito material não exigir a iniciativa da parte para essa desconsideração. $O$ fundamental é a observância do contraditório prévio para a concretização da desconsideração, já que essa é a finalidade essencial do incidente”. 
Revista Eletrônica de Direito Processual - REDP. Volume 16. Julho a dezembro de 2015

Periódico Semestral da Pós-Graduação Stricto Sensu em Direito Processual da UERJ

Patrono: José Carlos Barbosa Moreira. ISSN 1982-7636. pp. 436-448 http://www.e-publicacoes.uerj.br/index.php/redp/index

Não há como se concordar com a afirmação, mesmo para aqueles casos em que se esteja diante de direitos indisponíveis, tais como verbas alimentares, por exemplo. É que o incidente foi incluído no capítulo da intervenção de terceiro, e não se cogita admitir que a inclusão dos sócios se dê em caráter de litisconsórcio passivo necessário, senão facultativo (o enunciado 125 do Fórum Permanente de Processualistas Civis já havia assim expressado: "Há litisconsórcio passivo facultativo quando requerida a desconsideração da personalidade jurídica, juntamente com outro pedido formulado na petição inicial ou incidentemente no processo em curso").

O autor não pode ser ver obrigado a litigar em face do sócio, contra sua vontade, ainda mais quando se leva em conta a responsabilidade objetiva decorrente de eventuais danos causados no caso de que a desconsideração seja depois improcedente. Se fosse o caso de litisconsórcio necessário - mas não é -, então a inclusão seria forçada, e a sentença não produziria efeitos senão enquanto todos (os sócios) tivessem sido citados. A redação parece clara neste sentido, apontado para a necessidade de requerimento da parte, de modo que deve ser afastada a possibilidade de desconsideração de ofício pelo magistrado, como reconhece Teresa Arruda Alvim Wambier (2015): "não é possível a atuação do juiz sem provocação da parte (...) os pressupostos para a incidência deste mecanismo são diferentes em diversos ramos do direito material, mas a disciplina processual é uma só: em caso algum pode haver a instauração de ofício deste incidente".

Embora se admita a instauração do incidente em qualquer tempo, fase ou grau de jurisdição (art. 134), é de se excepcionar a instauração na fase do recurso especial ou extraordinário, posto que não se outorgou competência constitucional ao STJ ou STF para apreciação da matéria, sem contar a natureza devolutiva destes recursos (Wambier, 2015).

Não parece aqui que o novo CPC tenha estatuído regra de imprescritibilidade do direito de incluir o sócio ou a empresa no incidente de desconsideração. Há um entendimento em matéria tributária que vem sendo reiterado pelo STJ acerca do prazo para o redirecionamento da execução fiscal contra os sócios, no sentido de que, ainda que a citação válida da pessoa jurídica interrompa a prescrição em relação aos responsáveis solidários, 
Revista Eletrônica de Direito Processual - REDP. Volume 16. Julho a dezembro de 2015

Periódico Semestral da Pós-Graduação Stricto Sensu em Direito Processual da UERJ

Patrono: José Carlos Barbosa Moreira. ISSN 1982-7636. pp. 436-448 http://www.e-publicacoes.uerj.br/index.php/redp/index

verifica-se a prescrição se decorridos mais de cinco anos entre a citação da empresa e a citação dos sócios, de modo a não tornar imprescritível a dívida fiscal:

O Superior Tribunal de Justiça possui o firme entendimento de que a citação da sociedade executada interrompe a prescrição em relação aos seus sócios-gerentes para fins de redirecionamento da execução fiscal, que deverá ser promovida no prazo de cinco anos, prazo esse estipulado como medida de pacificação social e segurança jurídica, com a finalidade de evitar a imprescritibilidade das dívidas fiscais. (AgRg no Ag 1421601/SP, Rel. Ministro Napoleão Nunes Maia Filho, Primeira Turma, julgado em 17/03/2015, DJe 27/03/2015)

A interpretação pode evoluir também no sentido do reconhecimento da prescrição da desconsideração da personalidade jurídica em matéria de processo civil, levando em conta o prazo prescricional do próprio direito material envolvido, a partir do contexto sumulado pelo enunciado 150 do STF: "prescreve a execução no mesmo prazo de prescrição da ação".

A instauração do incidente, ou seja, o acolhimento do pedido de processamento do pedido de desconsideração, deve ser anotado na distribuição (art. 134, p. $1^{\circ}$ ), a fim de que se possa assegurar a terceiros o conhecimento acerca, evitando a prática de atos fraudulentos. Não basta o mero requerimento de instauração do incidente, mas sim o exercício de juízo não exauriente da plausibilidade das alegações, ainda que limitado à decisão que admite o incidente e manda citar o terceiro. Caso o pedido tenha sido formulado, mas não tenha sido sequer recepcionado pelo juiz (indeferimento de plano), não há razão para se comunicar o distribuidor.

Admitido o incidente, ou seja, determinada pelo juiz a citação do sócio ou da empresa, o processo seguirá suspenso até a decisão interlocutória (art. 134, p. $3^{\circ}$ ), sendo que eventual recurso não contará com efeito suspensivo, como regra. O incidente não exigirá propriamente a instauração de processo dependente, podendo ser decidido nos mesmo autos, a não ser que tal implique tumulto processual ou que a respectiva produção probatória seja extensa e complexa. Caso o pedido de desconsideração tenha sido formulado na própria inicial, não haverá suspensão do feito. 
Revista Eletrônica de Direito Processual - REDP. Volume 16. Julho a dezembro de 2015

Periódico Semestral da Pós-Graduação Stricto Sensu em Direito Processual da UERJ

Patrono: José Carlos Barbosa Moreira. ISSN 1982-7636. pp. 436-448 http://www.e-publicacoes.uerj.br/index.php/redp/index

Não há requisito formal específico estabelecido pelo novo Código de Processo Civil quanto ao pedido incidental de desconsideração (art. 134, p. $4^{\circ}$ ), a não ser quanto à determinação de que se demonstre "o preenchimento dos pressupostos legais específicos para desconsideração da personalidade jurídica”. A previsão é quanto ao direito material a ser aplicado pelo magistrado ao decidir sobre dever ou não ser desconsiderada a pessoa jurídica.

No plano do direito civil, do direito do consumidor e em outros ramos do direito material é que são previstos os requisitos específicos para incidência da teoria da desconsideração naquele ramo específico do direito. Deve o requerente indicar, desde logo, as provas que pretende produzir. Mas este dispositivo faz referência à uma dose mínima de "aparência do bom direito", de plausibilidade da alegação, sem o que o incidente pode e deve ser liminarmente indeferido (Wambier, 2015).

Com a instauração do incidente, o terceiro será citado para que se manifeste e requeira as provas cabíveis, no prazo de 15 dias. Marinoni (2015) entende que o prazo é comum se houverem mais de um sócio incluídos no pedido, e que não se aplicaria a causa de aumento de prazo (art. 229, NCPC) para litisconsortes com procuradores distintos, por se tratar de prazo próprio. Caso o réu não se manifeste a respeito, parece possível a aplicação da pena de revelia, com a presunção de veracidade dos fatos alegados pelo autor.

O próprio CPC qualifica de decisão interlocutória a decisão que resolve o incidente (art. 136), extirpando qualquer dúvida quanto ao recurso cabível, que é o agravo de instrumento (art. 1.015, IV, NCPC), ainda que equiparável à sentença, com o condão de produzir coisa julgada. É outra das exceções à regra de irrecorribilidade das interlocutórias apregoada pelo novo CPC. Por outro lado, caso o pedido incidental tenha sido formulado diretamente no tribunal, o recurso cabível será o agravo interno.

Destaca-se como principal efeito da procedência da desconsideração o de tornar possível que os atos executivos atinjam o patrimônio dos sócios, estendendo a responsabilidade patrimonial a um terceiro, que passa a ser réu (art. 137). Daí também 
Revista Eletrônica de Direito Processual - REDP. Volume 16. Julho a dezembro de 2015

Periódico Semestral da Pós-Graduação Stricto Sensu em Direito Processual da UERJ

Patrono: José Carlos Barbosa Moreira. ISSN 1982-7636. pp. 436-448 http://www.e-publicacoes.uerj.br/index.php/redp/index

decorre a ineficácia da alienação dos bens realizada por aquele a quem a responsabilidade foi estendida, se ocorrida em fraude à execução, caso preenchidos os requisitos legais, pois assim como ineficaz a alienação de um réu qualquer. Não ficou claro se os efeitos do deferimento da desconsideração retroagem à data da propositura da ação principal, ou se apenas quando da data do requerimento da inclusão do sócio, cabendo perquirir acerca do momento em que se deu o fato gerador da desconsideração, tal como a prática em excesso de poder ou a confusão patrimonial.

Juliano Gianechini Fernandes (2013), em análise do texto primitivo do projeto do novo CPC, que dispunha que sendo acolhido o pedido de aplicação da disregard doctrine, a alienação ou oneração de bens, havida em fraude de execução, após a instauração do incidente, será ineficaz em relação ao requerente, concluiu que "a norma gera, portanto, efeito ex tunc a tentativa do agente fraudador de se desfazer de seu patrimônio pessoal, preservando-se a possibilidade do terceiro adquirente de boa-fé, de postular em ação de regresso contra o sócio pessoa física, inclusive com nova possibilidade de requerer a desconsideração da personalidade jurídica, porém de forma inversa”.

Mas a redação sancionada do novo CPC suprimiu a previsão de que os efeitos se operavam "após a instauração do incidente". A caracterização da alienação ou oneração em fraude, por sua vez, se dá, entre outras razões, "quando, ao tempo da alienação ou da oneração, tramitava contra o devedor ação capaz de reduzi-lo à insolvência" (art. 792, IV, NCPC), e antes da instauração do incidente não há como se cogitar que tramitava ação contra o sócio, a não ser quer se admita forçosa e fictamente que os efeitos possam retroagir à data da propositura da ação principal. Já depois do requerimento de instauração do incidente, aí sim, é possível caracterizar-se a tramitação de ação capaz de reduzi-lo à insolvência, e também da possibilidade de que os efeitos possam retroagir àquela data, a não ser que se abandone por completo qualquer distinção entre a pessoa física e a pessoa jurídica, mas daí nem incidente algum era preciso, bastava, como vivencia na prática da Justiça do Trabalho, redirecionamento automático e sem qualquer critério da execução em face do sócios. A posição, contudo, encontra suporte na visão de Luis Alberto Reichelt (2015): 
Revista Eletrônica de Direito Processual - REDP. Volume 16. Julho a dezembro de 2015

Periódico Semestral da Pós-Graduação Stricto Sensu em Direito Processual da UERJ

Patrono: José Carlos Barbosa Moreira. ISSN 1982-7636. pp. 436-448 http://www.e-publicacoes.uerj.br/index.php/redp/index

Um dos grandes riscos à efetividade da desconsideração da personalidade jurídica é o de esvaziamento do patrimônio dos bens do sócio ou pessoa jurídica contra quem se pretende redirecionar o processo. Buscando coibir a prática de condutas tendentes a esse indesejável resultado, dispôs o art. 137 que acolhido o pedido de desconsideração, a alienação ou oneração de bens, havida em fraude de execução, será ineficaz em relação ao requerente. A compreensão desse comando, por sua vez, reclama atenção para o constante do art. 808, § 3..$^{\circ}$, do mesmo projeto de lei, segundo o qual, em se tratando de desconsideração da personalidade jurídica, a fraude à execução verifica-se a partir da citação da parte cuja personalidade se pretende desconsiderar. Por força disso, a alienação de bens do sócio é ineficaz desde a data em que a pessoa jurídica à qual ele está ligado foi inicialmente citada no processo, e essa ineficácia pode se operar antes mesmo de o sócio haver sido citado por força da desconsideração da personalidade jurídica. $\mathrm{O}$ mesmo raciocínio em termos de dinâmica no tempo pode ser implementado em se tratando de alienação de bens da pessoa jurídica nos casos em que, originalmente proposta a ação em face do seu sócio, seja pleiteada a desconsideração inversa da personalidade jurídica.

A posição merece crítica, pois embora valorize a dimensão da efetividade que se deve conferir ao processo, também implica injustificada presunção de má-fé na prática de atos pelo sócio, e de extensão de efeitos decorrentes da citação a pessoa que nem era parte no processo. $\mathrm{O}$ valor efetividade não é absoluto e não pode sacrificar todos os demais princípios processuais apenas para dar conta da satisfação material da execução. Para isso se tem a ação pauliana, embora se reconheça que acaba tendo pouca utilidade na prática forense.

Questão a merecer também ponderação jurisprudencial diz respeito à condenação sucumbencial no incidente de desconsideração. Caso o incidente seja procedente, a condenação em favor do advogado do autor se dará na própria sentença, ou, caso se trate de processo executivo ou já em execução, haverá apenas a extensão dos efeitos patrimoniais ao sócio, de forma que aqui não se antevê qualquer dificuldade. Mesmo quanto ao pedido de desconsideração formulado na inicial, que venha a ser afastado, também parece claro o cabimento da condenação em honorários. O questionamento que se coloca é em relação ao 
Revista Eletrônica de Direito Processual - REDP. Volume 16. Julho a dezembro de 2015

Periódico Semestral da Pós-Graduação Stricto Sensu em Direito Processual da UERJ

Patrono: José Carlos Barbosa Moreira. ISSN 1982-7636. pp. 436-448 http://www.e-publicacoes.uerj.br/index.php/redp/index

pedido incidental de desconsideração. É preciso lembrar que o instituto trata de modalidade de intervenção de terceiro, e já há um entendimento claro de que ante o princípio da causalidade deve ser (atualmente) imposta a condenação ao litisdenunciante perdedor, por exemplo: "Em atenção ao princípio da causalidade, o litisdenunciante que não se desincumbir de seu ônus probatório também arca com as despesas processuais e honorários advocatícios decorrentes da improcedência da denunciação da lide" (REsp 879.567/SP, Rel. Ministra Nancy Andrighi, Terceira Turma, julgado em 12/05/2009, DJe 29/05/2009).

Tendo o terceiro (o sócio ou a empresa) sido citado, constituído advogado, se manifestado em relação ao incidente e demonstrado que não era o caso da desconsideração da personalidade jurídica, há uma decorrência lógica de que o autor, que provocou o incidente, responda pelas custas e honorários do advogado, tanto pelo princípio da causalidade quanto pela proibição do enriquecimento ilícito. Não há como se isentar o autor dos ônus respectivos pela instauração de incidente infundado, a não ser que se crie figura imune aos ônus processuais. Esta é mais uma importante razão para que se afaste a possibilidade de inclusão de ofício, pelo juiz, do sócio ou da empresa, embora mesmo assim o autor siga responsável pelos ônus sucumbenciais.

Por fim, há um outro significativo aspecto envolvendo a desconsideração no tocante à responsabilidade pelos danos causados em decorrência de incidente infundado (art. 81, NCPC), tanto quanto às penas pela litigância de má-fé, quanto pelos demais prejuízos sofridos pela parte. É que a provocação do incidente infundado, além de lograr a caracterização do litigante improbo, pode efetivamente causar dano patrimonial ao terceiro, em especial na hipótese de que tenha sido adotado, cautelarmente alguma medida constritiva. Neste caso, ficará o autor obviamente responsável pela reparação dos danos.

Em conclusão, o novo CPC tratou de regular importante instrumento, resguardando em especial a dimensão do contraditório prévio para desconsideração da personalidade jurídica, e o fez bem na medida em que tirou do arbítrio jurisprudencial a fixação dos critérios. 
Revista Eletrônica de Direito Processual - REDP. Volume 16. Julho a dezembro de 2015

Periódico Semestral da Pós-Graduação Stricto Sensu em Direito Processual da UERJ

Patrono: José Carlos Barbosa Moreira. ISSN 1982-7636. pp. 436-448 http://www.e-publicacoes.uerj.br/index.php/redp/index

\section{REFERÊNCIAS BIBLIOGRÁFICAS}

COELHO, Fabio Ulhoa. A teoria maior e a teoria menor da desconsideração. Revista de Direito Bancário e do Mercado de Capitais - RDB, vol. 65/2014, p. 21/30, jul/set 2014. FERNANDES, Juliano Gianechini. Um ensaio sobre a teoria da desconsideração da personalidade jurídica inserida no projeto do novo código de processo civil brasileiro. Revista Páginas de Direito, Porto Alegre, ano 13, n 1074, 23 de agosto de 2013. Disponível em: http://www.tex.pro.br/home/artigos/174-artigos-ago-2013/4745-um-ensaio-sobre-ateoria-da-desconsideracao-da-personalidade-juridica-inserida-no-projeto-do-novo-codigode-processo-civil-brasileiro. Acesso em 24/06/2015.

MARINONI, Luiz Guilherme. Novo código de processo civil comentado [livro eletrônico]. São Paulo: Editora Revista dos Tribunais, 2015.

MEDINA, José Miguel Garcia. Novo Código de Processo Civil comentado. São Paulo: Editora Revista dos Tribunais, 2015.

PALHARES, Felipe. A aplicação da teoria da desconsideração inversa da personalidade jurídica à luz do ordenamento jurídico brasileiro. Revista de Direito Civil Contemporâneo, vol. 3/2015, p. 55/80, abr/jun 2015.

REICHELT, Luis Alberto. A desconsideração da personalidade jurídica no projeto de novo código de processo civil e a efetividade da tutela jurisdicional do consumidor. Revista de Direito do Consumidor, vol. 98/2015, p. 245-259, mar/abr 2015.

WAMBIER, Teresa Arruda Alvim (Coord.). Primeiros comentários ao novo código de processo civil [livro eletrônico]. São Paulo: Editora Revista dos Tribunais, 2015.

Enunciados do Fórum Permanente de Processualistas Civis. Disponível em $<$ http://portalprocessual.com/wp-content/uploads/2015/06/Carta-de-Vit\%C3\%B3ria.pdf $>$. Acesso em 25/06/2015. 